\title{
Private Incentives for Specialization in a Changing and Unpredictable Labor Market
}

\author{
Francisco Parro \\ Universidad Adolfo Ibáñez, Santiago, Chile \\ Email: fjparrog@gmail.com
}

Received 10 February 2015; accepted 20 March 2015; published 25 March 2015

Copyright (C) 2015 by author and Scientific Research Publishing Inc.

This work is licensed under the Creative Commons Attribution International License (CC BY). http://creativecommons.org/licenses/by/4.0/

(c) (i) Open Access

\begin{abstract}
Technological change is a distinctive characteristic of modern labor markets. New technologies change the demand for different skills in the labor market and thus introduce uncertainty in the wage structure that agents will face in the future. In this way, technological change affects agents decisions about which skills to invest in. In this paper, I study how labor market uncertainty arising from technological change influences the private incentives for specialization. I show that in a world populated by risk-averse agents, technologies that generate a positive covariance of wages across sectors or tasks within sectors will strengthen the incentives for specialization, whereas technological progress that generates a negative covariance of wages will generate strong private incentives for agents to become generalists. Therefore, there is no unique relationship between technological progress and specialization. The nature of the new technologies introduced in the labor market is what matters.
\end{abstract}

\section{Keywords}

Specialization, Human Capital, Technological Change

\section{Introduction}

Rosen [1] emphasizes that incentives for specialization are shown to arise from increasing returns to utilization of human capital. He points out that the return to investment in a particular skill is increasing in its subsequent rate of utilization because investment costs are independent of how acquired skills are employed. This fixed cost 
of investment makes it advantageous for identically skill-endowed individuals to specialize in a narrow band of skills and employ them as intensively as possible. Therefore, according to Rosen [1], increasing returns are the main private incentives for specialization. If those incentives are strong enough, specialization would be limited only by the extent of the market, as argued by Adam Smith in his 1965 book, The Wealth of Nations. ${ }^{1}$

Becker and Murphy [4] claim that even though limited markets sometimes curtail the division of labor, the degree of specialization is more often determined by other considerations. They assign special roles to the cost of coordinating specialized workers who perform complementary tasks, and to the amount of general knowledge available. According to their view, specialization increases until the higher productivity from a greater division of labor is just balanced by the greater costs of coordinating a larger number of more specialized workers. Additionally, greater knowledge derived from technological progress tends to raise the benefits from specialization and, thus, tends to raise the optimal division of labor.

In this paper I deviate from the previous literature to study how labor market uncertainty changes the private incentives for specialization. My focus is on technological change, which causes the skills demanded in the labor market in the future to become unpredictable. For instance, the introduction of certain technologies could replace some tasks and complement others. ${ }^{2}$ In that case, agents investing in skills that perform specific tasks face the risk that their qualifications could rapidly become obsolete if new technologies replace those tasks in the future labor market. They can diversify that risk if they invest in a second skill that complements those new technologies. On the contrary, if new technologies substitute or complement all tasks in the same way such possibilities for diversification does not exist. Thus, the nature of technological progress can strongly change the private incentives for specialization.

Therefore, workers who are deciding on which skills to specialize in must consider not only the fixed element embodied in human capital investment (the element highlighted by Rosen [1]) but also the joint distribution of wages in the economy generated by technological progress. In this way, even though technological change provides incentives to acquire increasingly specialized skills (as pointed out by Becker and Murphy [4]), there are some aspects of technological change that could decrease the incentives for specialization. A key aspect of the analysis is the sign and magnitude of the covariance of wages generated by technological progress; thus, the nature of the new technologies introduced in the labor market is what matters.

I show that a technological change that generates a positive covariance of wages in the economy could strengthen the private incentives for specialization even in a world populated by risk-averse individuals. For instance, assume that people expect that new technologies will cause wages in the economy to move together. That could be the case with skill-neutral technological change that increases or decreases the productivity of all workers across all sectors. In that case, even though agents are risk averse, they have greater private incentives for specialization compared with a scenario without uncertainty. On the contrary, if technological change generates a negative covariance of wages across different sectors or tasks within sectors of the economy, the incentives to become a generalist are greater. In this case, agents could be willing to pay the fixed cost of investing in a second skill in order to reduce their risk exposure. The central point is that to understand how an uncertain labor market changes private incentives for specialization, we must understand the nature of the technological change.

The rest of the paper is organized as follows. Section 2 develops the model. Section 3 presents and discusses the main results of the analysis. Finally, Section 4 concludes.

\section{The Model}

Assume an economy with two activities. Those activities could be considered two sectors of the economy or two tasks within a sector. Each activity requires an investment in a different skill. Denote by $h_{i}$ is human capital level needed to perform activity $i$. Human capital augments the efficiency of an agent's time in each activity. Let $t_{i}$ represent the amount of market time allocated to activity $i$. Then, the amount of useful work an agent supplies to activity $i$ is $t_{i} h_{i}$, measured in efficiency units. I normalize to one the total endowment of market time of each agent.

Imagine competitive labor markets under stationary conditions that establish efficiency wage rates in each

${ }^{1}$ Baumgartner [2] and Kim [3] also study factors that limit specialization. Those papers also point to the extent of the market as a natural limit for specialization.

${ }^{2}$ See, for instance, Autor, Levy and Murnane [5], Autor, Katz and Kearney [6], Goos and Manning [7], Acemoglu and Autor [8], among others. 
skill. Let $w_{i}$ denote these wages discounted to present value in activity $i$. I assume that wages in each activity or task depend mainly on the rate of technological change in the economy. Technological progress changes the demand for different skills in the economy and, thus, affects the wage structure. To capture this idea, I impose a simple reduced functional form for wages per unit of market time, $w_{i}=A_{i} h_{i}$. Assume that $A_{1}$ and $A_{2}$ are random variables with a jointly normal distribution with $A \sim N(\mu, \Omega)$ where $\mu$ is a vector of means and $\Omega$ is a matrix of variance-covariance with typical elements $\mu(i)$ and $\Omega(i, j)$, respectively.

Agents must invest in human capital to get the necessary skills to work in the labor market. As in Rosen [1], I assume that the return to investment in a particular skill is increasing in its subsequent rate of utilization because investments costs are independent of how acquired skills are employed. As Rosen [1] highlights, increasing returns to utilization are the main private incentives for specialization. Denote by $C\left(h_{1}, h_{2}\right)$ the investment cost function. I assume that this investment is made before entering the labor market and that it is irreversible. Additionally, in order to make explicit the private incentives for specialization in the model, I assume a separable cost function:

$$
C\left(h_{1}, h_{2}\right)=C\left(h_{1}\right)+C\left(h_{2}\right)=\alpha_{1} h_{1}+\alpha_{2} h_{2}
$$

Note that the subsequent utilization rate of skills, $t$, is not an argument of the cost function, which is the main source of increasing returns to specialization. Regarding preferences, assume that the utility function of each agent of the economy is given by the following exponential function:

$$
v\left(x\left(t_{1}\right)\right)=(-1 / \rho) \exp \left(-\rho x\left(t_{1}\right)\right)
$$

were $t_{1}$ is the amount of time allocated to activity (task) 1 and, thus, $t_{2}=1-t_{1}$. The parameter $\rho$ is the coefficient of absolute risk aversion. $x\left(t_{1}\right)$ denotes the consumption level of an agent that allocate $t_{1}$ units of her time to task 1 , which is given by their total labor income net of the costs of investing in the corresponding skills. Notice that $x\left(t_{1}\right)$ is a linear combination of random variables that are jointly normally distributed. Hence, $x\left(t_{1}\right)$ is itself normally distributed. We can then use the properties of a lognormally distributed random variable to obtain $E\left(v\left(x\left(t_{1}\right)\right)\right)=\frac{-1}{\rho} \exp \left(-\rho E\left(x\left(t_{1}\right)\right)+\frac{\rho^{2}}{2} \operatorname{Var}\left(x\left(t_{1}\right)\right)\right)$.

Additionally, we have that the expected value and variance of consumption are:

$$
\begin{gathered}
E\left(x\left(t_{1}\right)\right)=t_{1} h_{1} \mu(1)+\left(1-t_{1}\right) h_{2} \mu(2)-\alpha_{1} h_{1} I_{t_{1}>0}-\alpha_{2} h_{2} I_{t_{2}>0} \\
\operatorname{Var}\left(x\left(t_{1}\right)\right)=\left(t_{1}\right)^{2}\left(h_{1}\right)^{2} \Omega(1,1)+\left(1-t_{1}\right)^{2}\left(h_{2}\right)^{2} \Omega(2,2)+2 t_{1}\left(1-t_{1}\right) h_{1} h_{2} \Omega(1,2)
\end{gathered}
$$

where $I_{t_{i}>0}$ is an indicator that takes the value of one if agents invest a positive amount of time in skill $i$ (for $i=\{1,2\})$ and zero otherwise.

In order to facilitate the solution to the maximization problem of agents, consider the increasing transformation $f: R_{-} \rightarrow R$,

$$
f(u)=\frac{-1}{\rho} \log (-\rho u)
$$

where $u\left(t_{1}\right)=E\left[v\left(x\left(t_{1}\right)\right)\right]$. Then,

$$
V\left(t_{1}\right)=f\left(u\left(t_{1}\right)\right)=E\left(x\left(t_{1}\right)\right)-\left(\frac{\rho}{2}\right) \operatorname{Var}\left(x\left(t_{1}\right)\right)
$$

Since $f$ is a monotone transformation of $u\left(t_{1}\right)$, we may use $V\left(t_{1}\right)$ as our simplified objective function.

Finally, consider the following assumptions:

$$
\begin{gathered}
h_{1}=h_{2}=h \\
\mu(1)=\mu(2)=\mu \\
\alpha_{1}=\alpha_{2}=\alpha
\end{gathered}
$$

Those assumptions are useful because they allow us to focus the analysis on how labor market uncertainty 
changes the private incentives for specialization. Therefore, I leave aside any differences in the expected return earned in different sectors or in the costs of acquiring different skills. Therefore, my focus is on uncertainty that arises mainly from technological change.

Considering the assumptions described by Equations (7) to (9), the optimization problem faced by an agent that must decide the amount of time allocated to task 1 and 2 is ${ }^{3}$ :

$$
V\left(t_{1}\right)=\max _{t_{1}}\left\{\mu h-\alpha h\left(I_{t_{1}>0}+I_{t_{2}>0}\right)-\frac{\rho}{2}\left[\left(t_{1}\right)^{2} h^{2} \Omega(1,1)+\left(1-t_{1}\right)^{2} h^{2} \Omega(2,2)+2 t_{1}\left(1-t_{1}\right) h^{2} \Omega(1,2)\right]\right\}
$$

Therefore, the optimization problem that agents must solve consists of allocating their endowment of market time in order to minimize their exposure to risk and the fixed costs of investments in skills. In this sense, this problem is similar to a portfolio problem where agents choose their optimal purchases of securities to choose an optimal combination of risk and return. In this case, because of the assumptions described by Equations (7) to (9), the expected value of both "assets" is the same; thus, risk-averse agents will choose the "portfolio" that minimizes the risk exposure. However, the cost of this type of financial diversification comes from the fact that agents must invest in additional skills and, thus, cannot reap the benefits from the increasing returns derived from specialization highlighted by Rosen [1].

Notice that we can re-express the optimization problem faced by agents as follow:

$$
V\left(t_{1}\right)=\mu h+\min _{t_{1}}\left\{W\left(t_{1}\right)\right\}
$$

where

$$
W\left(t_{1}\right)=\alpha h\left(I_{t_{1}>0}+I_{t_{2}>0}\right)+\frac{\rho}{2}\left[\left(t_{1}\right)^{2} h^{2} \Omega(1,1)+\left(1-t_{1}\right)^{2} h^{2} \Omega(2,2)+2 t_{1}\left(1-t_{1}\right) h^{2} \Omega(1,2)\right]
$$

\section{Results}

To characterize the solution of the optimization problem described by (11), I will make three different assumptions regarding the covariance between wages in sectors/tasks 1 and $2, \Omega(1,2)$. Without loss of generality, assume that $\Omega(1,1)=\Omega(2,2)=\Omega$. The following three propositions discuss all potential cases:

Proposition 1 If $\Omega(1,2)=0$, agents will not specialize when the risk aversion and/or uncertainty are quantitatively important.

Proof. Agents must minimize $W\left(t_{1}\right)$. Then, in the case of complete specialization in task $i$, we have that $W\left(t_{i}=1\right)=\left(\frac{\rho}{2}\right) h^{2} \Omega+\alpha$. Additionally, consider an interior solution where agents are generalists. It is clear from (11) that the strategy that minimizes the risk exposure of agents is $t_{1}=t_{2}=0.5$. In that case, we have that $W\left(t_{1}=0.5\right)=\left(\frac{\rho}{4}\right) h^{2} \Omega+2 \alpha$. Therefore, we have that $W\left(t_{1}=0.5\right)<W\left(t_{i}=1\right)$ if and only if $\rho h^{2} \Omega>4 \alpha$.

First, notice that in the case of specialization, agents will choose the sector with the lower variance. If the variance of wages is the same in both sectors, agents would be indifferent between them. When agents choose to be generalists (in the sense that they invest in more than one skill), they must pay the cost of investing in both skills, that is, $2 \alpha$, independently of the fraction of the market time allocated to each sector. Therefore, they will allocate their time in order to minimize the risk exposure, which occurs when $t_{1}=0.5$.

This reduction in the risk exposure when agents are generalists will be more important when the degree of agents? Risk aversion and/or uncertainty in the economy are greater. If those gains more than offset the extra cost of investing in a second skill, then agents will decide not to specialize.

Proposition 2. If $\Omega(1,2)>0$, agents are more likely to specialize than in the case where $\Omega(1,2)=0$.

Proof. We have that

\footnotetext{
${ }^{3}$ It could be the case that the agent maximizes her utility by investing $t_{1}=t_{2}=0$. We discard this corner solution by assuming that either agents are forced to invest a positive amount of time in one or both activities, or by imposing some restrictions to the relevant parameters of the model such that $V\left(t_{1}+t_{2}=0\right)<V\left(t_{1}+t_{2}=1\right)$ for all $\left\{t_{1}, t_{2}\right\}$ in $[0,1]$.
} 
$W\left(t_{1}=0.5, \Omega(1,2)>0\right)-W\left(t_{1}=1, \Omega(1,2)>0\right)=\left[\frac{\rho}{4} h^{2}(\Omega+\Omega(1,2))+2 \alpha\right]-\left[\left(\frac{\rho}{2}\right) h^{2} \Omega+\alpha\right]$. Define $\tilde{W}=W\left(t_{1}=0.5, \Omega(1,2)>0\right)-W\left(t_{1}=1, \Omega(1,2)>0\right)$. Then, $\frac{\partial \tilde{W}}{\partial \Omega(1,2)}>0$. Then, a positive covariance of wages increases the incentives for specialization.

A positive covariance of wages in sectors 1 and 2 (or tasks 1 and 2 within sectors) is an additional source that increases the risk exposure of agents. Therefore, agents do not reduce their risk exposure by investing in both skills, but they have to pay the fixed costs of those investments. As a result, when technological change generates a strong positive covariance of wages across sectors, agents are more likely to specialize.

Proposition 3. If $\Omega(1,2)<0$, agents are less likely to specialize than in the case where $\Omega(1,2)=0$.

Proof. This result can be directly derived from Proposition 2. The fact that $\frac{\partial \tilde{W}}{\partial \Omega(1,2)}>0$ automatically imply that a negative covariance of wages decreases the incentives for specialization.

Propositions (1) to (3) formalize the following intuitive idea. New technologies change the demand for different skills in the labor market. For instance, computer-related technologies could replace some tasks and complement others. Imagine the case of new softwares that replace the medical checkups performed by physicians type A but complement the medical checkups performed by physicians type B. Agents investing in specific skills type A face the risk that their qualifications can become obsolete when the new softwares are introduced in the labor market. This risk can be diversified if those agents invest in both skills A and B. Therefore, this type of technological progress (the introduction of new medical softwares) increases the incentives for agents to become less specialized compared with a case where, for instance, a new machine replaces or complements all tasks in the same way.

New technologies in the labor market that generate a negative covariance of wages across sectors introduce a possibility of risk diversification. With a negative covariance of wages, agents can diversify risks by investing in a second skill that pays higher (lower) wages in states where the other sector pays lower (higher) wages. This source of risk diversification is not valuable in the case where agents are risk neutral.

From propositions (1) to (3) we conclude that the nature of technological progress is a key to understand how labor market uncertainty affects the private incentives for specialization. Technologies that generate a positive covariance of wages across sectors or tasks within sectors increase the risk exposure of generalist agents. Thus, that type of technological change introduces strong private incentives for specialization. On the contrary, technologies that generate a negative covariance of wages across sectors reduce the risk exposure of agents who become generalists in the labor market. Therefore, those types of technologies discourage agents from specializing in a narrow set of skills.

\section{Conclusions}

Technological change is a distinctive characteristic of modern labor markets. New technologies change the demand for different skills. For instance, computer-related technologies could replace some tasks and complement others. As a result, agents investing in skills that can be easily replaced by new technologies face the risk that their qualifications could rapidly become obsolete in the future labor markets. However, agents can diversify that risk by investing in a second skill if that skill complements the new technologies that are being introduced in the labor market. Such possibilities for diversification do not exist if new technologies substitute or complement all tasks in an identical way.

Therefore, technologies that generate a positive covariance of wages across sectors or tasks within sectors will strengthen the incentives for specialization, whereas technological progress that generates a negative covariance of wages will generate strong private incentives for agents to become generalists.

In this paper I have shown that private incentives for specialization not only depend on the fixed cost component of the investment in human capital (Rosen, [1]) or the costs of coordinating different skills (Becker and Murphy, [4]), but also on the nature of the new technologies introduced in the labor market. Additionally, I have shown that there is no unique relationship between technological progress and specialization. To understand that relationship, we must understand the nature of the new technologies that are being implemented in the labor market. 
An interesting avenue for future research is to analyze how the conclusions of this paper change when a market of securities is introduced as an alternative source of diversification. Extending the model in this paper in that direction could also allow us to study the link between financial and education markets more deeply. For instance, a reduction in the costs of coordinate different complementary skills in the labor market would provide more incentives for specialization and, thus, would increase demand for securities in the financial market, affecting asset prices.

\section{References}

[1] Rosen, S. (1983) Specialization and Human Capital. Journal of Labor Economics, 1, 43-49. http://dx.doi.org/10.1086/298003

[2] Baumgartner, J.R. (1988) Physicians Services and the Division of Labor across Local Markets. Journal of Political Economy, 96, 948-982. http://dx.doi.org/10.1086/261571

[3] Kim, S. (1989) Labor Specialization and the Extent of the Market. Journal of Political Economy, 97, 692-705. http://dx.doi.org/10.1086/261622

[4] Becker, G.S. and Murphy, K.M. (1992) The Division of Labor, Coordination Costs, and Knowledge. Journal of Political Economy, 107, 1137-1160. http://dx.doi.org/10.2307/2118383

[5] Autor, D.H., Levy, F. and Murnane, R.J. (2003) The Skill Content of Recent Technological Change: An Empirical Investigation. Quarterly Journal of Economics, 118, 1279-1333.

[6] Autor, D.H., Katz, L.F. and Kearney, M.S. (2006) The Polarization of the US Labor Market. American Economic Review, 96, 189-194.

[7] Goos, M. and Manning, A. (2007) Lousy and Lovely Jobs: The Rising Polarization of Work in Britain. Review of Economics and Statistics, 89, 118-133. http://dx.doi.org/10.1162/rest.89.1.118

[8] Acemoglu, D. and Autor, D.H. (2010) Skills, Tasks and Technologies: Implications for Employment and Earnings. National Bureau of Economic Research Working Paper 16082, Cambridge. 